\title{
Archivos

\section{Left ventricle non-compaction cardiomyopathy: Different clinical scenarios and magnetic resonance imaging findings}

\author{
María Martín ${ }^{\mathrm{a}, *}$, Elena Santamarta ${ }^{\mathrm{b}}$, Cecilia Corros $^{\mathrm{a}}$, Eva María Benito ${ }^{\mathrm{a}}$, \\ Diego León ${ }^{a}$, Elena Velasco ${ }^{a}$, Ana García-Campos ${ }^{a}$, María Luisa Rodríguez ${ }^{a}$, \\ Jesús M. de la Hera ${ }^{a}$, Vicente Barriales ${ }^{a}$, Antonio Saiz ${ }^{b}$, José L. Lambert ${ }^{a}$ \\ ${ }^{a}$ Cardiology Department, Hospital Universitario Central de Asturias, Oviedo, Asturias, Spain \\ b Radiology Department, Hospital Universitario Central de Asturias, Oviedo, Asturias, Spain
}

Received 14 January 2012; accepted 27 December 2012

\section{KEYWORDS}

Left ventricle non-compaction cardiomyopathy; Cardiac-magnetic resonance imaging; Cardiomyopathy; Spain

\section{PALABRAS CLAVE Miocardiopatía no compactada; Cardiorresonancia magnética; Miocardiopatía; España}

\begin{abstract}
Left ventricle non-compaction cardiomyopathy is currently considered as a welldefined individual entity. However, it includes a broad spectrum of clinical, radiological and pathophysiological findings. In this review we describe 3 different scenarios of this entity: an isolated case with severe left ventricle dysfunction, an "associated" case in a patient with previous atrial septum defect and pulmonary stenosis and finally, as a finding in a patient with a transient cerebrovascular ischemic attack. In the 2 last cases, both asymptomatic, morphological criteria of left ventricle non-compaction were found but, ventricular function was normal and cardiac-MRI showed no late gadolinium hyperenhancement. Periodical follow-up and familial screening were recommended. Natural history and prognosis factors of this disease are still not well known. Further and longer series of patients with this diagnosis are needed to completely define radiological criteria, clinical presentation and evolution.
\end{abstract}

( 2012 Instituto Nacional de Cardiología Ignacio Chávez. Published by Masson Doyma México S.A. All rights reserved.

\section{Miocardiopatía no compactada: diferentes escenarios clínicos y hallazgos en cardiorresonancia magnética}

Resumen La miocardiopatía no compactada está considerada actualmente como una entidad independiente y bien definida. Sin embargo, presenta un espectro amplio de hallazgos clínicos, radiológicos y fisiopatológicos. En la presente revisión describimos 3 escenarios clínicos diferentes de dicha entidad: un caso con disfunción ventricular severa, un caso como entidad «asociada» a una cardiopatía congénita en un pacientes con un defecto del septo interauricular

\footnotetext{
* Corresponding author at: Cardiology Department, Hospital Universitario Central de Asturias, Julián Clavería s/n, 33006 Oviedo, Spain. E-mail address: mmartinf7@hotmail.com (M. Martín).
} 
previo y estenosis pulmonar, y finalmente, como un hallazgo casual en un paciente con un accidente cerebrovascular transitorio. En estos 2 últimos casos se encontraron criterios morfológicos de miocardiopatía no compactada con función ventricular normal y sin presencia de realce tardío de gadolinio en el estudio de cardio-RM. En todos ellos se recomendó estudio familiar. La historia natural y el pronóstico de esta anatomía patológica no son todavía del todo conocidos. Series mayores y seguimiento más largos son necesarios para definir completamente los criterios radiológicos, la presentación clínica y la evolución de esta fascinante entidad. (C) 2012 Instituto Nacional de Cardiología Ignacio Chávez. Publicado por Masson Doyma México S.A. Todos los derechos reservados.

\section{Introduction}

In June 2001, Dr. R. Jenni established in a series of 34 patients the morphological criteria for the echocardiographic diagnosis of isolated left ventricular non-compaction (IVNC) cardiomyopathy, allowing this way an accurate differentiation from other forms of left ventricle noncompaction. ${ }^{1}$

At that time Jenni described the criteria that in our days well known as Jenni's criteria of IVNC cardiomyopathy, the WHO classification of cardiomyopathies included this entity as an "unclassified" cardiomyopathy. However, at this moment, it is considered as a well-defined individual entity.

IVNC cardiomyopathy is thought to be a morphogenetic abnormality involving an arrest of compaction of the loose myocardial meshwork during fetal ontogenesis. Four morphological criteria were defined by Jenni as diagnostic criteria of this entity: (1) Coexisting cardiac abnormalities must be absent (it is isolated) and so other entities such as semilunar valve obstruction or left ventricle outflow tract obstruction should be ruled out. (2) A two layer structure is seen, with a compacted thin epicardial band and a much thicker non-compacted endocardial layer of trabecular meshwork with deep endomyocardial spaces. A maximal end systolic ratio of non-compacted to compacted layer of $>2(\mathrm{NC} / \mathrm{C}>2)$ is diagnostic. (3) The predominant localization of the pathology is mid-lateral, apical and mid inferior areas, according to the series of Jenni. And finally, the fourth ecocardiographic criteria was color Doppler evidence of deep perfused intertrabecular recesses. $^{1}$

Jenni criteria seem to be clear for establishing an accurate echocardiographic diagnosis. Since 2001 and as a result of the development of imaging modalities, especially cardiac magnetic resonance imaging (cardiac-MRI), literature about this is still not completely known, and fascinating entity has exponentially increased. As it has been published, MRI seems to provide better delineation of the extent of the abnormal trabeculation in patients with non-compaction of the left ventricular myocardium, showing wider areas of involvement than echocardiography. ${ }^{2}$ Non-compaction criteria by $M R I$ is defined as a ratio of non-compacted to compacted myocardium $>2.3$ at end-diastole. ${ }^{3}$

There is also a broad clinical spectrum and patients can present with dyspnea, chest pain, palpitations and stroke. It can also be an incidental finding, moreover, it can be "isolated" or "associated" to other congenital anomalies, and it can appear as a sporadic or a familial disease. ${ }^{4}$ The outcome of patients remains also unclear with some boasting a prolonged asymptomatic course to others displaying a rapid deterioration of left ventricle systolic function. ${ }^{5}$

In order to understand this complex and heterogeneous entity, we present three different scenarios of left ventricle non-compaction cardiomyopathy (LVNC): isolated, biventricular-associated to a congenital cardiac lesion and finally as a finding in a patient with an ischemic cerebral attack in which a patent foramen ovale was also present. They all were finally diagnosed by cardiac-MRI (1.5T, GE Healthcare, Inc.).

\section{Clinical Scenario 1: Severe and progressive left ventricle dysfunction}

A 44-year-old woman, complaining of dyspnea without cardiovascular risk factors, and without previous history of familial cardiomyopathy, was subjected to cardiovascular study. She was initially diagnosed of idiopathic cardiomyopathy by echocardiogram. Coronary arteries were normal and ECG showed a left bundle branch block. Cardiac-MRI was performed in order to evaluate the differential diagnosis of cardiomyopathy (Fig. $1 \mathrm{~A}$ and $\mathrm{B}$ ). It revealed $\mathrm{a}$ severe left ventricle dysfunction and showed a left ventricle non-compaction cardiomyopathy (apex, apical segments and anteroseptal, anterior and antero-lateral mid cavity segments with a maximum NC/C ratio of 2.5 ) with areas of intramyocardial late gadolinium hyperenhancement, reflecting myocardial fibrosis (Fig. 1C and D). Holter monitoring revealed non sustained ventricular tachycardia. She developed a clinical progressive deterioration and finally underwent heart transplantation. First degree relative screening was negative.

\section{Clinical Scenario 2: Biventricular non-compaction associated to a congenital anomaly}

A 20-year-old man with previous diagnosis of interatrial septum defect and pulmonary stenosis, both surgically corrected during childhood, was referred to our institution for cardiac-MRI study. He was asymptomatic and had no familial history of cardiomyopathy. Previous echocardiogram showed a normal ejection fraction of left ventricle with a hypertrophic and hypertrabeculated right ventricle.

Cardiac-MRI revealed a non-compaction left ventricle (apex, apical segments and anterior, antero-lateral and 


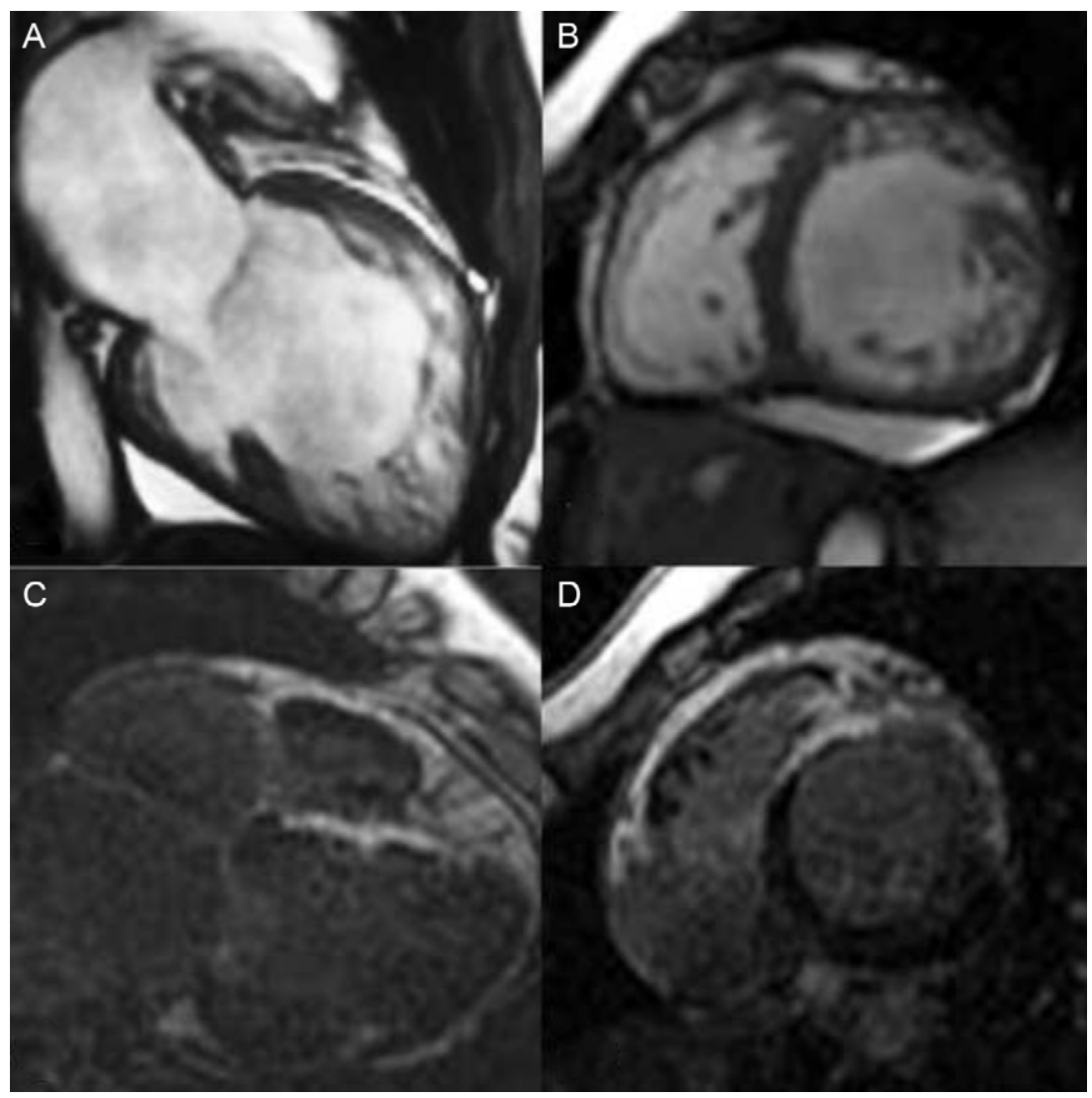

Figure 1 Cardiac-MRI: SSFP sequence and LGH sequence. Dilated left ventricle with non-compaction criteria and late gadolinium hyperenhancement reflecting fibrosis. (C and D) Ejection fraction was $30 \%{ }^{6}$

This figure was previously published in Revista Española de Cardiología, and it is reproduced with their authorization.

antero-septal mid cavity segments with $\mathrm{NC} / \mathrm{C}>2.6$ ) without areas of hypokinesis or late gadolinium hyperenhancement. Left ventricle volumes and systolic function were also normal (Fig. 2A and B). Right hypertrabeculation was also present related to residual pulmonary stenosis without definitive areas of non-compaction in the right ventricle. Final diagnosis was biventricular non-compaction cardiomyopathy and recommendations for periodical follow-up and familial screening were also made.

\section{Clinical Scenario 3: A finding in a patient with previous cerebrovascular ischemic attack}

A 34-year-old man, without cardiovascular risk factors, was subjected to transoesophageal echocardiogram after suffering a transient cerebrovascular ischemic attack, in order to search for patent foramen ovale. Physical exam was normal. Transoesophageal study revealed, not only a patent foramen ovale, which could justify the stroke, but also morphological

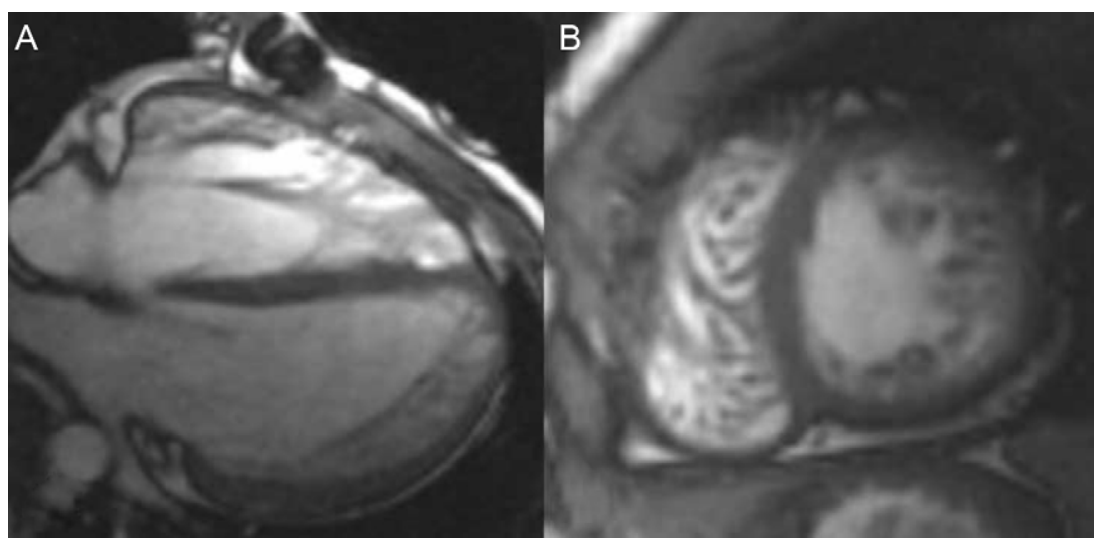

Figure 2 Cardiac-MRI. SSFP sequence. Non-compaction criteria in the lateral and inferior walls. Hypertrabeculation and noncompaction of right ventricle are also present. Ejection fraction was $60 \%$. Volumes were normal. 


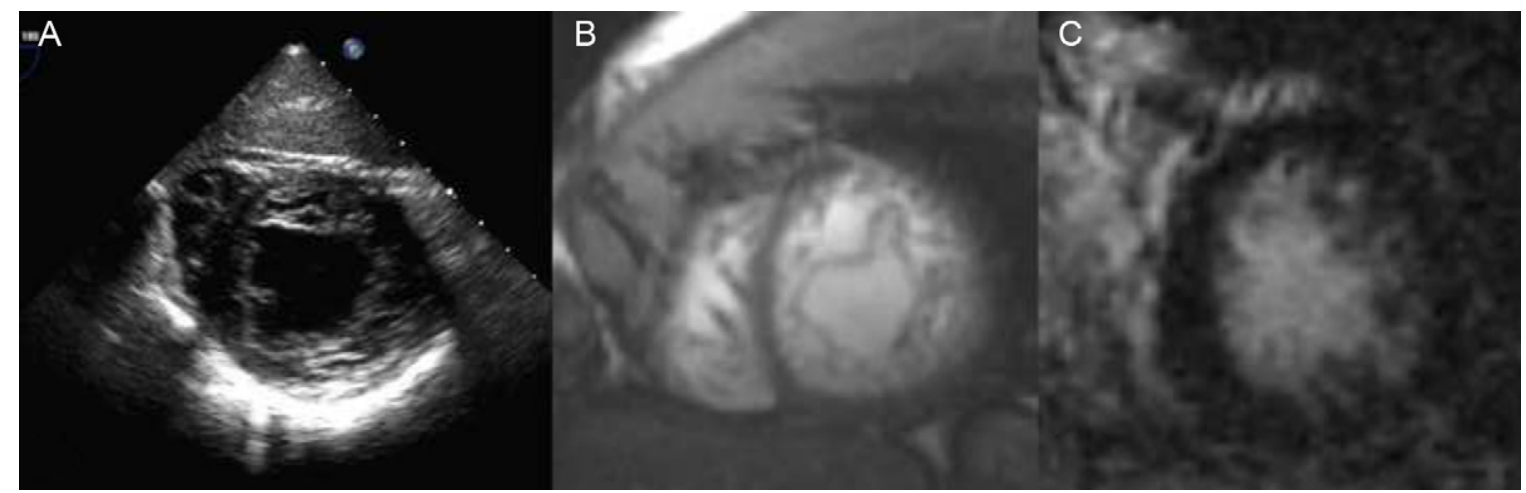

Figure 3 2D-Echocardiography (A) and cardiac-MRI (SSFP sequence (B) and short axis view 20 min after contrast injection (C)) showing non-compaction morphological criteria in the lateral an inferior walls both in echocardiogram and MRI. No LGH was present. Ejection fraction and volumes were normal.

criteria of left ventricle non-compaction cardiomyopathy (Fig. 3A). ECG showed a normal sinus rhythm and patient had no cardiological symptoms. Cardiac-MRI was practised, showing non-compaction criteria in inferior and lateral walls of the left ventricle, without hypokinesis and with absence of late gadolinium hyperenhancement. Both left ventricle volumes and ejection fraction were also normal (Fig. 3B and $\mathrm{C}$ ). Familial screening and patient follow up were also advised.

\section{Discussion}

As previously mentioned by other authors, LVNC cardiomyopathy is associated with a broad spectrum of clinical and pathophysiological findings. The genetic and clinical features, prognosis and characterization of this fascinating entity remain still incompletely known and it is a matter of interesting debate by the scientific community. Different mutations have been described related to LVNC, and mutations in $\alpha$-dystrobrevin have been identified in a Japanese family with LVNC. ${ }^{7}$

$\alpha$-Dystrobrevin is a component of the dystrophicassociated glycoprotein complex that links the cytoskeleton of cardiac myocytes to the extracellular matrix. LVNC has also been linked with mutations in the gene G4.5 at Xq28 which has also been implicated in the Barth syndrome. ${ }^{8}$ And finally, Cypher/Zasp mutations have also been identified in both familial DCM and isolated LVNC. ${ }^{9}$

About clinical scenarios, our first case seems to be a clear example of LVNC with a bad clinical evolution and prognosis. Presence of late gadolinium hyperenhancement $(\mathrm{LGH})$ is related to myocardial fibrosis and it probably represents a late stage of the disease. Delayed-enhancement confirms the presence of myocardial fibrosis and scarring in the hypertrabeculated myocardium, ${ }^{10}$ and it can represent a prognostic factor of the disease. Although in the present case fibrosis does not correspond exactly with the non-compaction area, it probably implies a global disease of the myocardium. Furthermore, fibrosis can be associated, both with ventricular arrhythmias and progressive left ventricular dysfunction and Holter monitoring of this patient exhibited ventricular tachycardia. For this reason the late gadolinium hyperenhancement sequence should always be included in the MRI diagnosis acquisition protocol when this entity is suspected.

The other two cases fulfill the morphological criteria of non-compaction cardiomyopathy with increased trabeculations, deep intertrabecular recesses and a noncompacted/compacted ratio $>2.3$ in cardiac-MRI but without other findings such as left ventricular dysfunction or hyperenhancement. Ventricular dilation and/or systolic impairment are common associated findings but are not a requisite for diagnosis.

The second case shows a different clinical scenario with a previous congenital cardiac malformation. ${ }^{11}$ Association with other entities such as obstruction of the right or left ventricular outflow tracts, complex cyanotic congenital heart disease, and coronary artery anomalies has also been described. Absence of left ventricle dysfunction and hyperenhancement could predict a good clinical outcome, or could simply represent an early stage of the disease. Anyway, both periodical follow up and familial screening are required. 5

And finally in the last case, diagnosis of LVNC could be considered as an incidental finding. Patent foramen ovale can be responsible of embolic attack in the young, although, we must not forget that embolic events can also be associated to LVNC. Thromboembolism is thought to result from stagnation of blood within the intertrabecular recesses and may manifest as cerebrovascular accidents, transient ischemic attacks, mesenteric infarction, or pulmonary embolism. In this case, as in the previous one, clinical and echocardiographic periodical follow-up are mandatory.

Therefore, we present three different scenarios of LVNC: isolated, associated and as a finding after a stroke. Presence of left ventricle dysfunction and LGH are of prognostic value, while normal function and absence of hyperenhancement can represent a good prognosis form of the illness, an initial stage of it, or even in the future it could be considered as a normal variant of the myocardium "a non-compaction like" myocardium. Of course, this conclusion will only be clarified after years of follow-up.

As it is recognized by other authors difficulties with LVNC begin just in the diagnosis criteria, as different timing of measurements, systole or diastole have been proposed. Besides, even for experts, making a final diagnosis can be difficult and in echocardiogram laboratories we have 
assisted to a great increase in non-compaction cardiomyopathy diagnosis or over diagnosis. Certainly, although both 3D and contrast echocardiography can improve the assessment of this cardiomyopathy, we must not forget that cardiacMRI can play an important role in its diagnosis. The spatial resolution of this technique, its ability for evaluating cardiac function and what is more, the tissue characterization by the late-gadolinium hyperenhancement sequence makes it an excellent tool for the diagnosis of cardiomyopathies, specially, in the case of non-compaction in which differential diagnosis with other entities, such a hypertrophic cardiomyopathy can be sometimes difficult. Late gadolinium enhancement is a surrogate of myocardial fibrosis, and as previously mentioned there seems to be a correlation of fibrosis with the clinical severity and the ventricular dysfunction in patients with non-compaction disease. ${ }^{12}$ So fibrosis represents a marker of bad prognosis which could be used as a stratification tool for these patients, similar to that proposed for hypertrophic cardiomyopathy.

Many questions are still open in left ventricle noncompaction disease, but cardiac-MRI can give us some of the answers: a more precise diagnosis based on a better endomyocardial definition and a tissue characterization which can help us to define patient prognosis.

Anyway, in all the cases, cardiac evaluation of family members is mandatory as the most common pattern of inheritance in LVNC is autosomal dominant. ${ }^{13}$

\section{Conclusions}

In conclusion, and as other authors have previously mentioned, LVNC can be associated with a wide spectrum of clinical and pathophysiological findings. ${ }^{5}$ It could be similar to hypertrophic cardiomyopathy that has a broad heterogeneity not only concerning disease-causing genetic mutations but also in terms of phenotypic expression, treatment and prognosis. Natural history and prognosis factors of LVNC cardiomyopathy are still not well known. Further and longer series of patients with this diagnosis are needed to define completely the radiological criteria, clinical presentation and evolution.

\section{Funding}

There was no funding for this job.

\section{Conflict of interests}

Authors do not have any conflict of interests.

\section{References}

1. Jenni R, Oechslin E, Schneider J, et al. Echocardiographic and pathoanatomical characteristics of isolated left ventricular non compaction: a step towards classifications as a distinct cardiomyopathy. Heart. 2001;86:666-71.

2. Alhabshan F, Smallhorn JF, Golding F, et al. Extent of myocardial non-compaction: comparison between MRI and echocardiographic evaluation. Pediatr Radiol. 2005;35: 1147-51.

3. Petersen SE, Selvanayagam JB, Weismann F, et al. Left ventricular on-compaction: insights from cardiovascular magnetic resonance imaging. J Am Coll Cardiol. 2005;46:101-5.

4. Tatu-Chitoiu A, Bradisteanu S. A rare case of biventricular non-compaction associated with ventricular septal defect and descendent aortic stenosis in a young man. Eur J Echocardiogr. 2008;9:306-8.

5. Lofiego C, Biagini E, Pasquale F, et al. Wide spectrum of presentation and variable outcomes of isolated left ventricular non-compaction. Heart. 2007;93:65-71.

6. Martín M, Santamarta E, Saiz A, et al. Realce tardío de gadolinio en la miocardiopatía no compactada. Rev Esp Cardiol. 2009;62:822-3.

7. Ichida F. Left ventricular noncompaction. Circ J. 2009;73:19-26.

8. Alter P, Maisch B. Non-compaction cardiomyopathy in an adult with hereditary spherocytosis. Eur J Heart Fail. 2007;9: 98-9.

9. Vatta M, Mohapatra B, Jimenez $S$, et al. Mutations in Cypher/ZASP in patients with dilated cardiomyopathy and left ventricular non-compaction. J Am Coll Cardiol. 2003;42:2014-27.

10. Jassal DS, Nomura CH, Neilan TG, et al. Delayed enhancement cardiac MR imaging in noncompaction of left ventricular myocardium. J Cardiovasc Magn Reson. 2006;8:489-91.

11. Patrignani A, D'Aroma A, Cicogna S. Unusual association between congenitally corrected transposition of the great arteries and non-compaction of the right systemic ventricle. Int J Cardiovasc Imaging. 2009;25:551-3.

12. Nucifora G, Aquaro GD, Pingitore A, et al. Myocardial fibrosis in isolated left ventricular non-compaction and its relation to disease severity. Eur J Heart Fail. 2011;13:170-6.

13. Oechslin E, Jenni R. Left ventricular non-compaction revisited: a distinct phenotype with genetic heterogeneity? Eur Heart J. 2011;32:1446-56. 